\title{
Primary Tumor Size Predicts Distant Metastasis of Mucosal Malignant Melanoma in Head and Neck
}

\author{
HIDENORI SUZUKI ${ }^{1}$, GAKU TAKANO ${ }^{2}$, NOBUHIRO HANAI ${ }^{1}$, DAISUKE NISHIKAWA ${ }^{1}$, \\ YUSUKE KOIDE $^{1}$, SHINTARO BEPPU ${ }^{1}$ and YASUHISA HASEGAWA ${ }^{3}$ \\ ${ }^{1}$ Department of Head and Neck Surgery, Aichi Cancer Center Hospital, Nagoya, Japan; \\ ${ }^{2}$ Department of Otolaryngology-Head and Neck Surgery, \\ Nagoya City University Graduate School of Medical Science, Nagoya, Japan; \\ ${ }^{3}$ Department of Head and Neck Surgery, Asahi University, Gifu, Japan
}

\begin{abstract}
Background/Aim: To investigate the possible association between primary tumor size and overall survival and/or distant metastasis-free survival of patients with mucosal malignant melanoma of the head and neck. Patients and Methods: A total of 25 patients that have had primary tumor resection were enrolled in this study. Primary tumor size was assessed as the maximum size of the primary tumor in pathological and surgical reports. Results: Patients with a primary tumor size of $\geq 43 \mathrm{~mm}$ showed a significant association with shorter overall survival $(p=0.007)$ and distant metastasis-free survival $(p=0.005)$ by the log-rank test. Multivariate survival analyses of two Cox's hazards proportional models showed that, in modell, $p T 4 a-4 b(p=0.01)$ and primary tumor size $\geq 43 \mathrm{~mm}(p=0.03)$ were significantly associated with shorter overall survival, and primary tumor size $\geq 43 \mathrm{~mm}(p=0.02)$ was significantly associated with shorter distant metastasisfree survival. In model2, pStage IVA-IVB $(p=0.02)$ and primary tumor size $\geq 43 \mathrm{~mm}$ ( $p=0.03$ ) were significantly associated with shorter overall survival, and primary tumor size $\geq 43 \mathrm{~mm}$ ( $p=0.02$ ) was significantly associated with shorter distant metastasis-free survival. Conclusion: Large tumor size $(\geq 43 \mathrm{~mm})$ is a predictor of shorter overall survival and distant metastasis-free survival after primary tumor resection of mucosal malignant melanoma of the head and neck.
\end{abstract}

Correspondence to: Hidenori Suzuki, Department of Head and Neck Surgery, Aichi Cancer Center Hospital, 1-1 Kanokoden, Chikusa-ku, Nagoya, 464-8681, Japan. Tel: +81 527626111, Fax: +81 527642963, e-mail: hi.suzuki@aichi-cc.jp

Key Words: Mucosal malignant melanoma in head and neck, overall survival, distant metastasis-free survival, primary tumor size, predictor.
Mucosal malignant melanoma of the head and neck (MMMHN) is rare, accounting for $0.2-0.8 \%$ of all malignant melanoma cases (1). Recent reviews reported that the American Joint Committee Cancer (AJCC) TNM staging system for MMMHN, which was proposed in 2009, is not fully acceptable (1-3). Several studies have researched useful predictors of MMMHN using various approaches such as clinical, pathological and biological methods (4-8).

Distant metastasis (DM) in MMMHN is a major factor that reduces overall survival (OS), which is generally less than $35 \%$ (2). The primary tumor size in MMMHN has also been reported to be a predictor of OS by several authors (4, 5). However, the association between the primary tumor size and DM in MMMHN has not been fully investigated.

Therefore, we investigated the possible association between the primary tumor size and OS in MMMHN, and examined whether or not the primary tumor size is associated with distant metastasis-free survival (DMFS).

\section{Patients and Methods}

Patients. Primary tumor resection with or without neck dissection was performed in 26 patients who were diagnosed with mucosal malignant melanoma, at the Department of Head and Neck Surgery, Aichi Cancer Center Hospital, between January 2004 and March 2015. After excluding one patient who had been diagnosed with mucosal malignant melanoma in the cervical esophagus, a total of 25 patients with MMMHN were enrolled in this study. This study was approved by the review board, and all patients provided their informed consent for the examinations and treatments.

Clinicopathological parameters. Clinical staging was determined by a routine physical examination, flexible nasopharyngeal endoscopy, enhanced cervical computed tomography or magnetic resonance imaging, and ${ }^{18} \mathrm{~F}$-fluorodeoxyglucose-positron emission tomography/ computed tomography, if possible. The 25 patients underwent en-bloc resection with or without free-flap reconstruction surgery. The regimen of chemotherapy was mostly dacarbazine, nimustine hydrochloride, vincristine and interferon-beta. The regimen of biotherapy was 
interferon-beta. Postoperative radiotherapy was performed without chemotherapy. After completion of the initial treatment, we tried to perform salvage surgery based on the presence of tumor recurrence. We reviewed the primary tumor sizes of all patients based on the maximum size of the primary tumor in pathological and surgical reports. From both the pathological reports and the records of intraoperative findings, we restaged the pathological $\mathrm{T}$ and $\mathrm{N}$ classification, pathological stage based on the eighth edition of Union for International Cancer Control TNM classification of Malignant Tumors as described previously (9).

Statistical analysis. Statistical analyses were performed using the JMP software package (version 9; SAS; Cary, NC, USA). The relationships between the primary tumor size and the clinicopathological parameters (age, sex, primary tumor site, pathological $\mathrm{T}$ and $\mathrm{N}$ classification, pathological stage, positive surgical margin, neck dissection, reconstruction surgery, chemotherapy, biotherapy, radiotherapy) were assessed by MannWhitney $U$-test. The survival time, which was calculated as the number of days from the start of any treatment to the specific target event or last contact, was estimated by the Kaplan-Meier method. The target events were death for the OS, local recurrence for the local recurrence-free survival, regional recurrence for the regional recurrence-free survival, and DM for the DMFS. In accordance with a previous report, various cut-off values of the primary tumor size were assessed by univariate analysis of the OS using log-rank test (10). The patients were divided into two groups based on the primary tumor size $(<43 \mathrm{~mm}$ or $\geq 43 \mathrm{~mm}$ ), and differences between the two groups were compared by univariate survival analysis using log-rank test. The associations between the two groups $(<43 \mathrm{~mm}$ or $\geq 43 \mathrm{~mm}$ ) with regard to the clinicopathological parameters were compared by using Fisher's exact test. Multivariate analyses of the factors associated with OS and DMFS used two Cox's proportional hazard models. Model 1 was adjusted with the pathological $\mathrm{T}$ classification (pT4a-4b/pT3), and model 2 was adjusted with the pathological stage (pStageIVA-IVB/pStageIII). $p$-Values $<0.05$ were considered to indicate statistical significance.

\section{Results}

Primary tumor size and clinicopathological parameters. The mean \pm standard deviation (SD) of the primary tumor size in all patients was $27 \pm 15 \mathrm{~mm}$ (range $=1-60 \mathrm{~mm}$ ). The relationships between the primary tumor size and the clinicopathological parameters are shown in Table I. No significant associations were observed. The association between the pathological $\mathrm{T}$ classification and the primary tumor size in all patients is shown in Figure 1.

Survival outcomes. At the end of the study, the mean \pm SD follow-up period was $1259 \pm 1203$ days among all patients, $1883 \pm 1299$ days for the 9 patients who remained alive, and $909 \pm 768$ days for the 16 patients who died. Local recurrence, regional recurrence and DM were found in 11,8 and 16 patients, respectively. Salvage surgery was performed on 3 patients with tumor recurrence. The 5-year rates for OS, local recurrence-free survival, regional recurrence-free survival, and DMFS were $45.3 \%, 50.9 \%, 63.8 \%$, and $37.9 \%$ respectively.
Table I. The relationships between primary tumor size and clinicopathological parameters $(n=25)$.

\begin{tabular}{|c|c|c|c|}
\hline Parameter & $\begin{array}{l}\text { Patient } \\
\text { number }\end{array}$ & $\begin{array}{c}\text { Primary tumor } \\
\text { size }(\mathrm{mm}) \\
\text { (mean } \pm \text { standard } \\
\text { deviation) }\end{array}$ & $p$-Value* \\
\hline \multicolumn{4}{|l|}{ Age } \\
\hline$<72$ & 12 & $21.3 \pm 16.4$ & \\
\hline$\geq 72$ & 13 & $31.4 \pm 12.4$ & 0.08 \\
\hline \multicolumn{4}{|l|}{ Gender } \\
\hline Male & 10 & $31.3 \pm 13.6$ & \\
\hline Female & 15 & $23.4 \pm 15.6$ & 0.12 \\
\hline \multicolumn{4}{|l|}{ Primary site } \\
\hline Oral & 12 & $28.8 \pm 13.7$ & \\
\hline Sinonasal tract & 13 & $24.5 \pm 16.5$ & 0.30 \\
\hline \multicolumn{4}{|c|}{ Pathological $\mathrm{T}$ classification } \\
\hline $\mathrm{T} 3$ & 11 & $21.1 \pm 15.4$ & \\
\hline $\mathrm{T} 4 \mathrm{a}-\mathrm{b}$ & 14 & $30.9 \pm 13.8$ & 0.12 \\
\hline \multicolumn{4}{|c|}{ Pathological $\mathrm{N}$ classification } \\
\hline N0,NX & 18 & $27.3 \pm 15.6$ & \\
\hline N1 & 7 & $24.6 \pm 14.5$ & 0.81 \\
\hline \multicolumn{4}{|l|}{ Pathological stage } \\
\hline III & 10 & $22.7 \pm 15.3$ & \\
\hline IVA-B & 15 & $29.1 \pm 14.9$ & 0.33 \\
\hline \multicolumn{4}{|c|}{ Positive surgical margin } \\
\hline Presence & 4 & $31.8 \pm 15.1$ & \\
\hline Absence & 21 & $25.6 \pm 15.2$ & 0.41 \\
\hline \multicolumn{4}{|l|}{ Neck dissection } \\
\hline Presence & 12 & $31.0 \pm 14.9$ & \\
\hline Absence & 13 & $22.5 \pm 14.6$ & 0.10 \\
\hline \multicolumn{4}{|l|}{ Reconstruction } \\
\hline Presence & 9 & $34.0 \pm 15.8$ & \\
\hline Absence & 16 & $22.4 \pm 13.4$ & 0.07 \\
\hline \multicolumn{4}{|l|}{ Chemotherapy } \\
\hline Presence & 17 & $24.9 \pm 15.9$ & \\
\hline Absence & 8 & $30.1 \pm 13.4$ & 0.38 \\
\hline \multicolumn{4}{|l|}{ Biotherapy } \\
\hline Presence & 17 & $26.4 \pm 15.1$ & \\
\hline Absence & 8 & $27.0 \pm 16.1$ & 0.95 \\
\hline \multicolumn{4}{|l|}{ Radiotherapy } \\
\hline Presence & 3 & $31.7 \pm 18.7$ & \\
\hline Absence & 22 & $25.9 \pm 14.9$ & 0.68 \\
\hline
\end{tabular}

*Mann-Whitney $U$-test.

Cut-off values of primary tumor size and univariate analysis. The cut-off values of the primary tumor size and $p$-values in the OS analysis are shown in Figure 2. The primary tumor size of $43 \mathrm{~mm}$ allowed for the differentiation of the shorter OS group (primary tumor size $\geq 43 \mathrm{~mm}$ ) from the longer OS group (primary tumor size $<43 \mathrm{~mm}$ ) by the log-rank test $(p=0.007$ ). Patients with a primary tumor size $\geq 43 \mathrm{~mm}$ were significantly associated with shorter DMFS than those with primary tumor size $<43 \mathrm{~mm}(p=0.005)$. In contrast, the local recurrence-free survival $(p=0.09)$ and regional recurrence-free survival $(p=0.06)$ did not differ significantly in the patients with primary tumor size $\geq 43 \mathrm{~mm}$. The Kaplan-Meier curves for the OS and 
Primary tumor size ( $\mathrm{mm})$

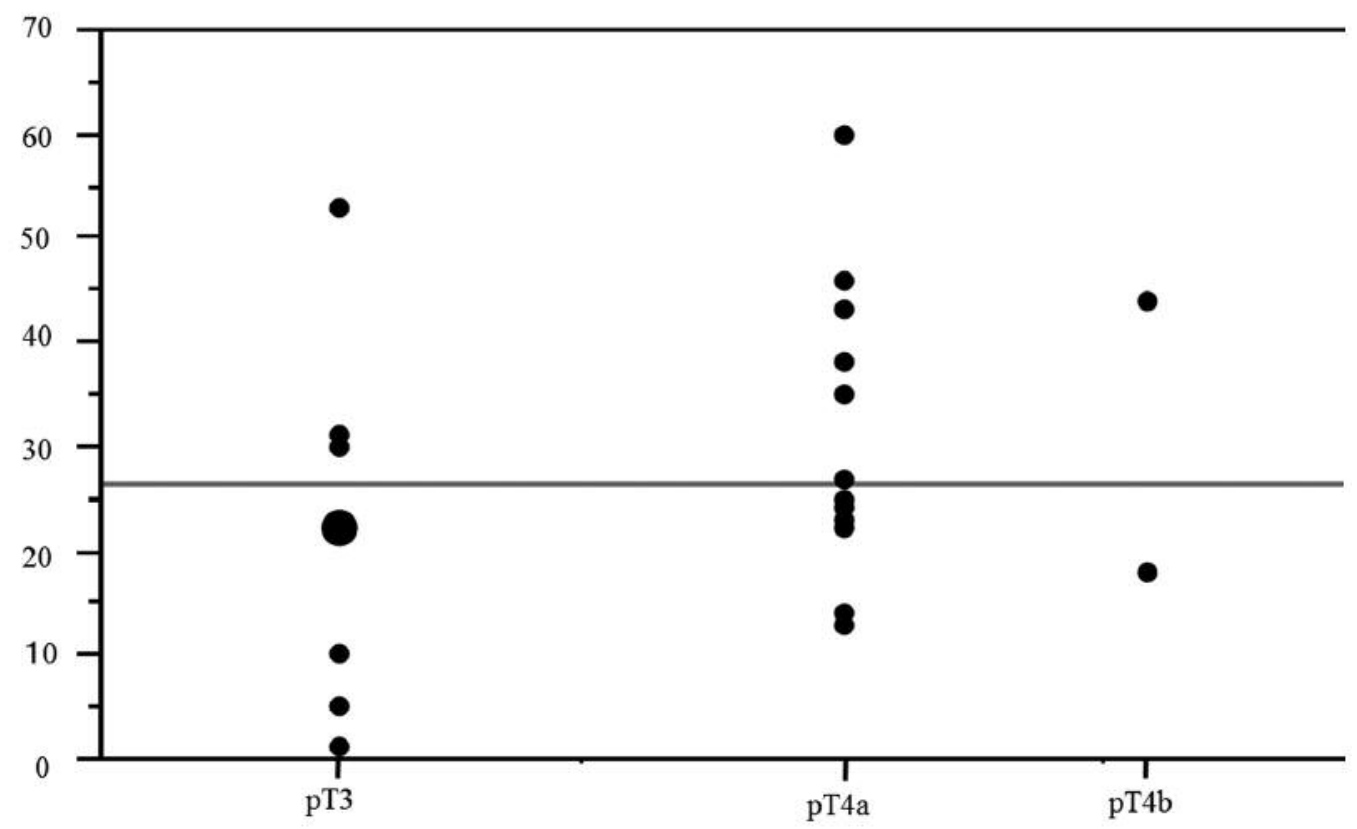

Figure 1. The association between the pathological T classification and the primary tumor size of 25 patients with mucosal malignant melanoma in the head and neck.

$p$-value of log-rank test in overall survival

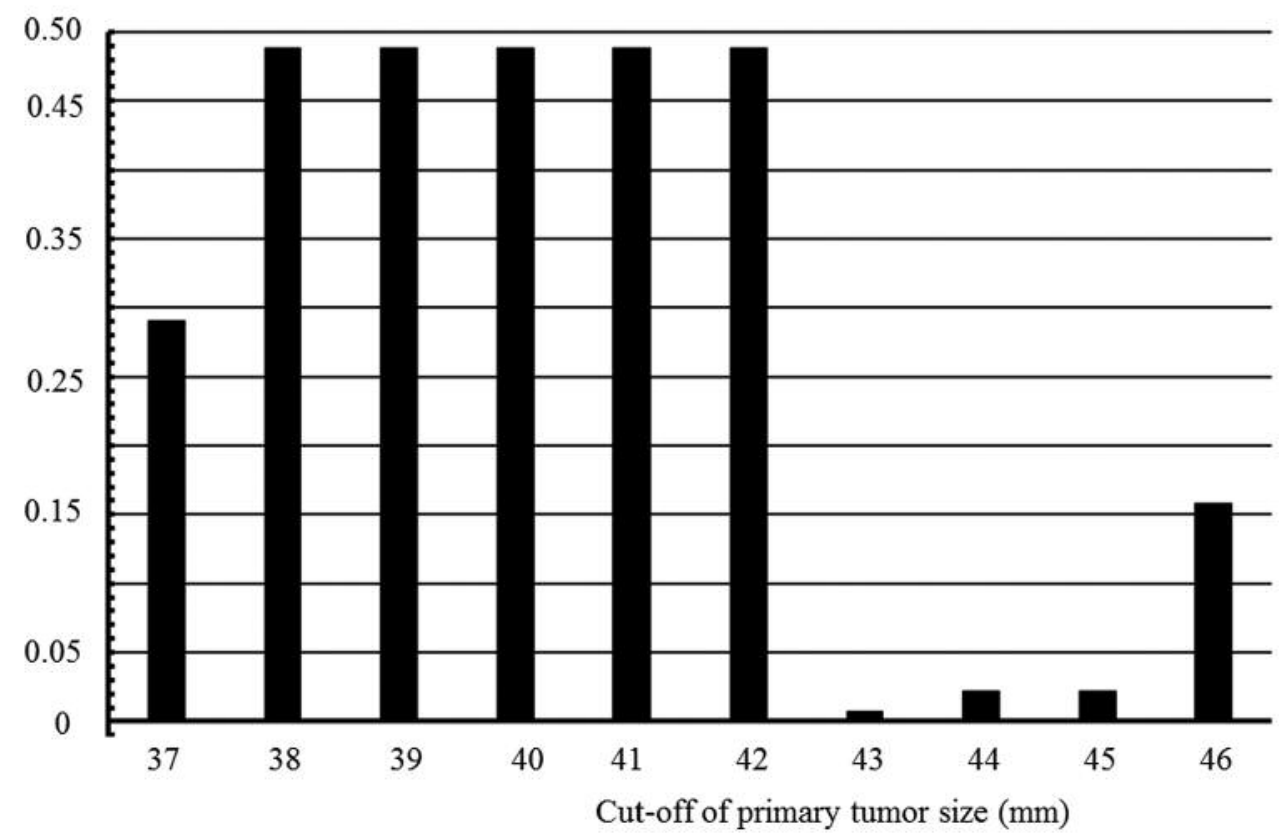

Figure 2. The p-values of the log-rank test for the overall survival using different cut-off values for the primary tumor size of 25 patients with malignant melanoma in the head and neck. 
Overall survival rate

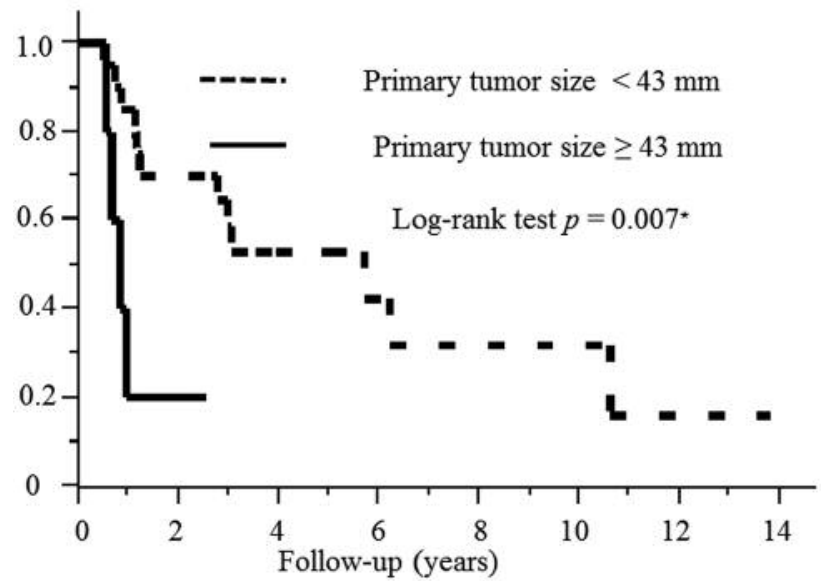

Distant metastasis-free survival rate

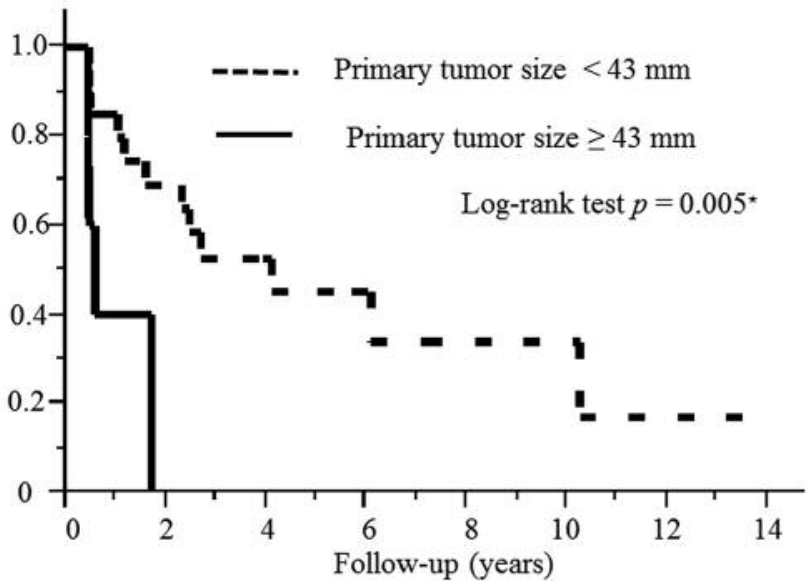

Figure 3. The association between the primary tumor size and the survival of 25 patients with mucosal malignant melanoma in the head and neck (Kaplan-Meier method). A primary tumor size $\geq 43 \mathrm{~mm}$ was found to be associated with a significantly lower overall survival and distant metastasis-free survival.
Table II. Relationships between primary tumor size and clinicopathological parameters $(n=25)$.

\begin{tabular}{|c|c|c|c|}
\hline \multirow[t]{2}{*}{ Parameter } & \multicolumn{2}{|c|}{ Primary tumor size } & \multirow[t]{2}{*}{$p$-Value* } \\
\hline & $\begin{array}{l}<43 \mathrm{~mm} \\
(\mathrm{n}=20)\end{array}$ & $\begin{array}{c}\geq 43 \mathrm{~mm} \\
\quad(\mathrm{n}=5)\end{array}$ & \\
\hline \multicolumn{4}{|l|}{ Age } \\
\hline$<72$ & 11 & 1 & \multirow[t]{2}{*}{0.32} \\
\hline$\geq 72$ & 9 & 4 & \\
\hline \multicolumn{4}{|l|}{ Gender } \\
\hline Male & 7 & 3 & \multirow[t]{2}{*}{0.36} \\
\hline Female & 13 & 2 & \\
\hline \multicolumn{4}{|l|}{ Primary tumor site } \\
\hline Oral & 9 & 3 & \multirow[t]{2}{*}{0.65} \\
\hline Sinonasal tract & 11 & 2 & \\
\hline \multicolumn{4}{|c|}{ Pathological $\mathrm{T}$ classification } \\
\hline $\mathrm{T} 3$ & 10 & 1 & \multirow[t]{2}{*}{0.34} \\
\hline $\mathrm{T} 4 \mathrm{a}-\mathrm{T} 4 \mathrm{~b}$ & 10 & 4 & \\
\hline \multicolumn{4}{|c|}{ Pathological $\mathrm{N}$ classification } \\
\hline NO-NX & 14 & 4 & \multirow[t]{2}{*}{1.00} \\
\hline N1 & 6 & 1 & \\
\hline \multicolumn{4}{|l|}{ Pathological stage } \\
\hline III & 9 & 1 & \multirow[t]{2}{*}{0.61} \\
\hline IVA-IVB & 11 & 4 & \\
\hline \multicolumn{4}{|c|}{ Positive surgical margin } \\
\hline Presence & 3 & 1 & \multirow[t]{2}{*}{1.00} \\
\hline Absence & 17 & 4 & \\
\hline \multicolumn{4}{|l|}{ Neck dissection } \\
\hline Presence & 8 & 4 & \multirow[t]{2}{*}{0.16} \\
\hline Absence & 12 & 1 & \\
\hline \multicolumn{4}{|c|}{ Reconstruction surgery } \\
\hline Presence & 5 & 4 & \multirow[t]{2}{*}{0.04} \\
\hline Absence & 15 & 1 & \\
\hline \multicolumn{4}{|l|}{ Chemotherapy } \\
\hline Presence & 14 & 3 & \multirow[t]{2}{*}{1.00} \\
\hline Absence & 6 & 2 & \\
\hline \multicolumn{4}{|l|}{ Biotherapy } \\
\hline Presence & 14 & 3 & \multirow[t]{2}{*}{1.00} \\
\hline Absence & 6 & 2 & \\
\hline \multicolumn{4}{|l|}{ Radiotherapy } \\
\hline Presence & 2 & 1 & \multirow[t]{2}{*}{0.50} \\
\hline Absence & 18 & 4 & \\
\hline
\end{tabular}

*Fisher's exact test.

pStageIVA-IVB $(p=0.02)$ and primary tumor size $\geq 43 \mathrm{~mm}$ $(p=0.03)$ were significantly associated with shorter OS, and primary tumor size $\geq 43 \mathrm{~mm}(p=0.02)$ was significantly associated with shorter DMFS.

\section{Discussion}

In the present study, it was shown for the first time that primary tumor size of $\geq 43 \mathrm{~mm}$ was significantly associated with shorter OS and DMFS in patients with MMMHN.

MMMHN, which accounts for $0.03 \%$ of all cancer diagnoses, was an aggressive and rare tumor (3). Regardless 
Table III. The multivariate survival analysis* of mucosal malignant melanoma in head and neck.

\begin{tabular}{|c|c|c|c|c|c|c|}
\hline \multirow[t]{2}{*}{ Parameter } & \multicolumn{3}{|c|}{ Overall survival } & \multicolumn{3}{|c|}{ Distant metastasis-free survival } \\
\hline & HR & $95 \% \mathrm{CI}$ & $p$-Value & HR & $95 \% \mathrm{CI}$ & $p$-Value \\
\hline \multicolumn{7}{|l|}{ Model-1 } \\
\hline Pathological T classification (pT4a-4b/pT3) & 4.17 & $1.40-15.3$ & 0.01 & 1.93 & $0.69-5.63$ & 0.21 \\
\hline Primary tumor size $(\geq 43 \mathrm{~mm} /<43 \mathrm{~mm})$ & 4.95 & $1.15-20.0$ & 0.03 & 5.29 & $1.28-20.0$ & 0.02 \\
\hline \multicolumn{7}{|l|}{ Model-2 } \\
\hline Pathological stage (pStageIVA-IVB/pStageIII) & 3.51 & $1.18-12.9$ & 0.02 & 1.61 & $0.58-4.70$ & 0.36 \\
\hline Primary tumor size $(\geq 43 \mathrm{~mm} /<43 \mathrm{~mm})$ & 5.26 & $1.23-21.1$ & 0.03 & 5.41 & $1.32-20.3$ & 0.02 \\
\hline
\end{tabular}

*Cox proportional hazard model was used.

of the radical surgery with or without adjuvant treatments for MMMHN, local recurrence, regional recurrence, and DM occurred in up to $81 \%$ of patients (6). Although the seventh edition of AJCC Cancer Staging Manual described the TNM classification for MMMHN (11), several prognostic parameters, such as an advanced $\mathrm{T}$ category, were shown not to be consistent findings in reports of MMMHN (1). Recent reviews suggested that further accumulation of data regarding predictors of MMMHN is necessary (1-3). Indeed, Houette et al. detected a significant association between the staging system and OS in 18 patients with sinonasal mucosal melanoma (7).

Several authors have observed a significant association between primary tumor size and OS $(4,5)$. For example, tumor size $\geq 40 \mathrm{~mm}$ in 815 patients with MMMHN from the Surveillance, Epidemiology, and End Results Program was found to be a significant predictor of OS in univariate and multivariate analyses (4), and tumor size $\geq 40 \mathrm{~mm}$ in 51 patients with TanyN0M0 of oral mucosal melanoma was associated with a worse OS than patients with a tumor size $<40 \mathrm{~mm}$ (5). The findings of the present study revealed significant associations between the tumor size and the OS and are in good agreement with these previous studies $(4,5)$.

Because several reviews on MMMHN have reported that DM is directly associated with a shorter OS (1-4), we hypothesized that the primary tumor size was associated with DM. Indeed, in the present study, we showed that tumor size $\geq 43 \mathrm{~mm}$ was significantly associated with shorter DMFS. The findings of the present study suggested that the tumor size in MMMHN is a predictor of identifying patients that are at high risk of developing DM. Furthermore, we believe that the significant association between primary tumor size of $\geq 43 \mathrm{~mm}$ and shorter OS was caused by the shorter DMFS.

The limitations of the present study were the relatively small number of subjects and its retrospective design. A future prospective study in a larger cohort and in a multi-institutional setting is expected to yield more accurate results.

\section{Conclusion}

A large primary tumor size ( $\geq 43 \mathrm{~mm}$ ) is a predictor of shorter OS and DMFS in patients with MMMHN who undergo surgery.

\section{Conflicts of Interest}

All of the Authors declare that they have no conflicts of interest.

\section{Acknowledgements}

This study was supported by the JSPS KAKENHI Grant Number $16 \mathrm{~K} 11253$.

\section{References}

1 Ascierto PA, Accorona R, Botti G, Farina D, Fossati P, Gatta G, Gogas H, Lombardi D, Maroldi R, Nicolai P, Ravanelli M and Vanella V: Mucosal melanoma of the head and neck. Crit Rev Oncol Hematol 112: 136-152, 2017.

2 López F, Rodrigo JP, Cardesa A, Triantafyllou A, Devaney KO, Mendenhall WM, Haigentz M Jr., Strojan P, Pellitteri PK, Bradford CR, Shaha AR, Hunt JL, de Bree R, Takes RP, Rinaldo A and Ferlito A: Update on primary head and neck mucosal melanoma. Head Neck 38: 147-155, 2016.

3 Green B, Elhamshary A, Gomez R, Rahimi S and Brennan PA: An update on the current management of head and neck mucosal melanoma. J Oral Pathol Med 46: 475-479, 2017.

4 Jethanamest D, Vila PM, Sikora AG and Morris LG: Predictors of survival in mucosal melanoma of the head and neck. Ann Surg Oncol 18: 2748-2756, 2011.

5 Sun CZ, Chen YF, Jiang YE, Hu ZD, Yang AK and Song M: Treatment and prognosis of oral mucosal melanoma. Oral Oncol 48: 647-652, 2012.

6 Michel J, Perret-Court A, Fakhry N, Braustein D, Monestier S, Richard MA, Grob JJ, Giovanni A and Dessi P: Sinonasal mucosal melanomas: the prognostic value of tumor classifications. Head Neck 36: 311-316, 2014. 
7 Houette A, Gilain L, Mulliez A, Mom T and Saroul N: Prognostic value of two tumour staging classifications in patients with sinonasal mucosal melanoma. Eur Ann Otorhinolaryngol Head Neck Dis 133: 313-317, 2016.

8 Çomoğlu Ş, Polat B, Çelik M, Sahin B, Enver N, Keles MN and Sari SO: Prognostic factors in head and neck mucosal malignant melanoma. Auris Nasus Larynx 45: 135-142, 2018.

9 Suzuki H, Koide Y, Hanai N, Nishikawa D, Beppu S, Mikami S and Hasegawa Y: Lymph node density in papillary thyroid carcinoma is a prognostic factor after adjusting for pathological stage. Oncotarget 9: 26670-26678, 2018.
10 Suzuki H, Matoba T, Hanai N, Nishikawa D, Fukuda Y, Koide $\mathrm{Y}$ and Hasegawa $\mathrm{Y}$ : Lymph node ratio predicts survival in hypopharyngeal cancer with positive lymph node metastasis. Eur Arch Otorhinolaryngol 273: 4595-4600, 2016.

11 Edge SB and Compton CC: The American Joint Committee on Cancer: the 7th edition of the AJCC cancer staging manual and the future of TNM. Ann Surg Oncol 17: 1471-1474, 2010.

Received August 1, 2018

Revised October 10, 2018 Accepted October 12, 2018 